\title{
Three stage supply chain model with two warehouse, imperfect production, variable demand rate and inflation
}

\author{
S.R. Singh ${ }^{\mathrm{a}}$, Vandana Gupta ${ }^{\mathrm{b} *}$ and Preety Gupta ${ }^{\mathrm{a}}$
}

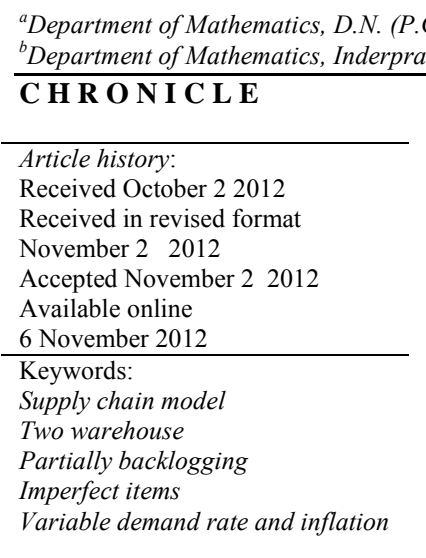

\section{Introduction}

This model is a collaboration of the vendor, supplier and buyer. In this theory supplier uses the own warehouse (OW) and rented warehouse (RW) for the excess inventory. Many researchers explained the concept of two warehouses but none of them has discussed in the supply chain model. For example, Hartley (1976) first proposed a two-warehouse inventory system. Goswami and Chaudhuri (1992) developed an economic order quantity model for items with two levels of storage for a linear trend in demand. Bhunia and Maiti (1998) presented two warehouses inventory model for deteriorating items with a linear trend in demand and shortages. Yang (2004) discussed two warehouse inventory models for deteriorating items with shortages under inflation. Yang (2006) developed two warehouse partial backlogging inventory models for deteriorating items under inflation. Das et al. (2007) established two warehouse supply-chain models under possibility/necessity/credibility measures. Lee and Hsu (2009) considered two warehouse production models for deteriorating inventory items with time-dependent

\footnotetext{
* Corresponding author.

E-mail: vandana.vandana1983@gmail.com (V. Gupta)

(C) 2013 Growing Science Ltd. All rights reserved. doi: $10.5267 /$ j.ijiec.2012.010.005
} 
demands. Geraldine and Yves (2010) developed an integrated model for warehouse and inventory planning.

Many inventory models follows that all units produced are of perfect quality but in practice this assumption is improbable. In fact, product quality is not always perfect but directly affected by the reliability of the production process used to produce the products. Porteus (1986) and Rosenblatt and Lee (1986) are among the first to explicitly elaborate on the significant relationship between quality imperfect and lot size. Khouja and Mehrez (1994) described an economic production lot size model with imperfect quality and variable production rate. Lin (1999) explained an integrated productioninventory model with imperfect production processes and a limited capacity for raw materials. Salameh and Jaber (2000) established a model on economic production quantity model for items with imperfect quantity. Chung and Hou (2003) developed an optimal production runtime with imperfect production processes and allowable shortages. Chung and Huang (2006) explained retailer's optimal cycle times in the EOQ model with imperfect quantity and a permissible credit period. Wee et al. (2007) developed an optimal inventory model for items with imperfect quality and shortage backordering. Maddah and Jaber (2008) explained an economic order quantity for items with imperfect quality. Chung et al. (2009) developed a two-warehouse inventory model with imperfect quality production processes. Chen and Kang (2010) described a relationship between vendor and buyer by considering trade credit and items of imperfect quality. Sarkar and Moon (2011) established an EPQ model with inflation in an imperfect production system. Hsu (2012) developed an optimal production policy with investment on imperfect production processes.

Generally demand rate depends on stock or time such as large number of goods display in the market will lead the customer to buy more and for some items, demand rate depends on time. Baker and Urban (1988) explained a deterministic inventory system with an inventory level-dependent demand rate. Mandal and Maiti (1997) described an inventory model for damageable items with stock-dependent demand and shortages. Balkhi and Benkherouf (2004) proposed an inventory model for deteriorating items with stock dependent and time-varying demand rates. Chern et al. (2008) established partial backlogging inventory lot size models for deteriorating items with fluctuating demand under inflation. Yang et al. (2010) developed an inventory model under inflation for deteriorating items with stock dependent consumption rate and partial backlogging shortages. Giri and chakraborty (2011) described supply chain coordination for a deteriorating product under stock-dependent consumption rate and unreliable production process.

All the above researchers have explained the theory of variable demand rate, imperfect items, two warehouse, partial backlogging and inflation in isolation. These all concepts are associated with each other. In this model, there is a collaboration of these factors in the supply chain model. If vendor produces the items then obviously some items will be imperfect and since the demand rate in not always constant, therefore for the vendor and supplier, it is time dependent and for the buyer demand rate is stock dependent. Here supplier uses the rented warehouse and own warehouse for the storage of excess inventory. The concept of partial backlogging also considered on the buyer's part. Since when shortage occurs then some customer will wait for backorder and others will turn to buy from other sellers so partial backlogging is more realistic. In this model we collaborate all the realistic factors and we can analyze the changes occurs in the total cost with the help of numerical example. The objective of this model is to determine the optimal value of length of the production time and total cost. Thus this paper gives a unique theory on supply chain management.

\section{Assumptions and notation:}

The mathematical model is developed based on the following assumptions:

1) The replenishment rate is infinite and lead time is zero. 
2) The demand rate for the vendor and supplier is time dependent i.e $\alpha+\beta$ t, where $\alpha$ and $\beta$ are positive constants.

3) The demand rate for the buyer is stock dependent which is represented by $D(t)$ at time $t$ is

$$
D(t)=\left\{\begin{array}{cc}
a+b I(t) & I(t)>0 \\
a & I(t)=0
\end{array}\right.
$$

where $\mathrm{a}, \mathrm{b}$ are positive constants and $\mathrm{I}(\mathrm{t})$ is the inventory level at time $\mathrm{t}$.

4) Shortages are allowed on the buyer's part. Unsatisfied demand is partial backlogged. The fraction of shortages backordered is a differentiable and decreasing function of time $t$, denoted by $\delta(t)$, where $t$ is the waiting time up to the next replenishment, and $0 \leq \delta(t) \leq 1$ with $\delta(0)=1$. Note that if $\delta(t)=1$ (or 0 ) for all $t$, then shortages are completely backlogged (or lost).

5) Constant deterioration rate is considered. For the supplier there is a variation in the deterioration rate for the OW and RW.

6) Inflation is considered.

7) The OW has a fixed capacity of W units.

8) The RW has unlimited capacity.

9) The total inventory costs in RW are higher than those in OW.

10) At the start of each production cycle, the production process is in an in-control state producing quality items. During a production run, the production process may shift from an in-control state to an out-of-control state. Once the production process shifts to an out-of-control state, the shift cannot be detected until the end of the production cycle, and a fixed proportion of the produced items are defective. All defective items are detected at the end of each production cycle, and there is a rework cost for defective items. The rework occurs on a different production process. This study considers its rework cost only.

11) Multiple deliveries per order are considered.

The following notations are used throughout the whole paper:

$\begin{array}{ll}T & \text { Time length for each Cycle, } \\ T_{1} & \text { The production period, } \\ T_{2} & \text { The non production period, } \\ P & \text { Production rate per unit, } \\ C_{1 v} & \text { Holding cost of the vendor per unit, } \\ C_{2 v} & \text { Deterioration Cost for the vendor per unit, } \\ C_{3 v} & \text { Vendor's set up cost per production cycle, } \\ C_{4 v} & \text { Rework cost for the imperfect items, } \\ C_{1 s o} & \text { Holding cost in OW for the supplier, } \\ C_{1 s r} & \text { Holding cost in RW for the supplier, } \\ C_{2 s} & \text { Supplier's deterioration cost per unit, } \\ C_{3 s} & \text { Supplier's set up cost per order, } \\ \Theta & \text { Deterioration rate for vendor and buyer, where } 0<\Theta<1, \\ \zeta & \text { Deterioration rate in OW of the supplier where } 0<\zeta<1, \\ \eta & \text { Deterioration rate in RW of the supplier, where } 0<\eta<1, \eta<\zeta, \\ W & \text { Capacity of OW, } \\ \mathrm{C}_{1 \mathrm{~b}} & \text { Buyer's holding cost per unit, } \\ \mathrm{C}_{2 \mathrm{~b}} & \text { Buyer's deterioration per unit, } \\ \mathrm{C}_{3 \mathrm{~b}} & \text { Buyer's set up cost per production cycle, } \\ \mathrm{C}_{4 \mathrm{~b}} & \text { Shortage cost per unit, } \\ \mathrm{C}_{5 \mathrm{~b}} & \text { Lost sale cost per unit for the buyer, }\end{array}$


$\mathrm{k} \quad$ percentage of the defective items,

$\mathrm{n} \quad$ Number of deliveries for the supplier,

$\mathrm{m} \quad$ Number of deliveries for the buyer,

$\delta \quad$ partial backlogging rate,

$\mathrm{r} \quad$ Inflation rate,

$\mathrm{T} / \mathrm{n} \quad$ One delivery time for supplier which is equal to $\mathrm{T}_{3}+\mathrm{T}_{4}$,

$\mathrm{T} / \mathrm{mn} \quad$ One delivery time for buyer which is equal to $\mathrm{T}_{5}+\mathrm{T}_{6}$,

\section{Model development}

In this integrated model, we focused on vendor, supplier and buyer cooperation. There are three stages in our model. The first stage is the vendor's production system. The vendor produces the items and delivers to the supplier. The second stage is the supplier's inventory system. Supplier uses the rented and own warehouse for the excess inventory; deliver the items to the buyer with multiple deliveries. The third stage is the buyer's inventory system.

\subsection{Vendor's inventory model}

The vendor's inventory system in Fig. 3a can be divided into two independent phases depicted by $T 1$ and $T 2$. During $T 1$ time period, there is an inventory buildup due to the production and decreases due to the demand and deterioration. Some imperfect items are produced during the production. At $t=T 1$ the production stops and the inventory level increases to its maximum inventory level $M I_{v}$. Now there is no production during $T 2$ time period and inventory level decreases due to demand and deterioration. The inventory level becomes zero at $\mathrm{t}=\mathrm{T} 2$.

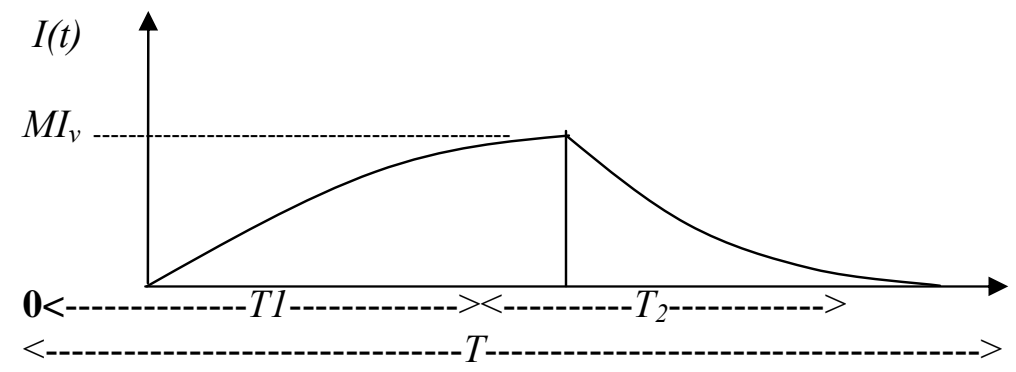

Fig. 1(a) Vendor's inventory system

In this subsection, the behavior of the inventory in a cycle can be represented by the following equations.

$$
\begin{array}{ll}
I_{v 1}{ }^{\prime}(t)+\theta I_{v 1}(t)=P-(\alpha+\beta t), & 0 \leq t \leq T_{1} \\
I_{v 2}{ }^{\prime}(t)+\theta I_{v 2}(t)=-(\alpha+\beta t), & 0 \leq t \leq T_{2}
\end{array}
$$

Using the boundary conditions $I_{v 1}(0)=0 \operatorname{and} I_{v 2}\left(T_{2}\right)=0$, the solutions of the above differential equations are

$$
\begin{array}{ll}
I_{v 1}(t)=\left(\frac{P-\alpha}{\theta}+\frac{\beta}{\theta^{2}}\right)\left(1-e^{-\theta t}\right)-\frac{\beta t}{\theta} & 0 \leq t \leq T_{1} \\
I_{v 2}(t)=\left(\frac{\alpha}{\theta}-\frac{\beta}{\theta^{2}}\right)\left(e^{\theta\left(T_{2}-t\right)}-1\right)+\frac{\beta}{\theta}\left(T_{2} e^{\theta\left(T_{2}-t\right)}-t\right) & 0 \leq t \leq T_{2}
\end{array}
$$

Vendor has the maximum inventory $M I_{v}=\left(\frac{P-\alpha}{\theta}+\frac{\beta}{\theta^{2}}\right)\left(1-e^{-\theta T_{1}}\right)-\frac{\beta T_{1}}{\theta}$ 
Present worth holding cost is

$$
\begin{aligned}
& H C_{v}=C_{1 v}\left[\int_{0}^{T_{1}} I_{v 1}(t) e^{-r t} d t+e^{-r T_{1}} \int_{0}^{T_{2}} I_{v 2}(t) e^{-r t} d t\right] \\
& H C_{v}=C_{1 v}\left[\begin{array}{l}
\left(\frac{p-\alpha}{\theta}+\frac{\beta}{\theta^{2}}\right)\left\{\frac{\theta-(\theta+r) e^{-r T_{1}}+r e^{-(\theta+r) T_{1}}}{r(\theta+r)}\right\}+\frac{\beta}{\theta}\left(\frac{T_{1} e^{-r T_{1}}}{r}+\frac{\left(e^{-r T_{1}}-1\right)}{r^{2}}\right) \\
\left.+e^{-r T_{1}}\left\{\left(\frac{e^{\theta T_{2}}-e^{-r T_{2}}}{\theta+r}\right)\left(\frac{\alpha+\beta T_{2}}{\theta}-\frac{\beta}{\theta^{2}}\right)+\frac{\left(e^{-r T_{2}}-1\right)}{r}\left(\frac{\beta}{\theta r}-\frac{(\alpha \theta-\beta)}{\theta^{2}}\right)+\frac{\beta T_{2} e^{-r T_{2}}}{\theta r}\right\}\right]
\end{array}\right.
\end{aligned}
$$

Present worth deterioration cost is

$$
\begin{aligned}
& D C=C_{2 v} \theta\left[\int_{0}^{T_{1}} I_{v 1}(t) e^{-r t} d t+e^{-r T_{1}} \int_{0}^{T_{2}} I_{v 2}(t) e^{-r t} d t\right] \\
& =C_{2 v} \theta\left[\begin{array}{l}
\left(\frac{p-\alpha}{\theta}+\frac{\beta}{\theta^{2}}\right)\left\{\frac{\theta-(\theta+r) e^{-r T_{1}}+r e^{-(\theta+r) T_{1}}}{r(\theta+r)}\right\}+\frac{\beta}{\theta}\left(\frac{T_{1} e^{-r T_{1}}}{r}+\frac{\left(e^{-r T_{1}}-1\right)}{r^{2}}\right) \\
\left.+e^{-r T_{1}}\left\{\left(\frac{e^{\theta T_{2}}-e^{-r T_{2}}}{\theta+r}\right)\left(\frac{\alpha+\beta T_{2}}{\theta}-\frac{\beta}{\theta^{2}}\right)+\frac{\left(e^{-r T_{2}}-1\right)}{r}\left(\frac{\beta}{\theta r}-\frac{(\alpha \theta-\beta)}{\theta^{2}}\right)+\frac{\beta T_{2} e^{-r T_{2}}}{\theta r}\right\}\right]
\end{array}\right.
\end{aligned}
$$

Present worth set up cost is

$S C_{v}=C_{3 v}$

Number of defective items

There are two cases. First, if the machine turns to out-of-control state after the time production time $\mathrm{T}_{1}$, then there will be no defective items, but if the machine is in out-of-control state before the time $\mathrm{T}_{1}$, then there will be defective items as given below:

$$
N=\left\{\begin{array}{cc}
0 & X \geq T_{1} \\
k \int_{X}^{T_{1}} P d t & X<T_{1}
\end{array}\right\} \quad N=T_{1}\left\{\begin{array}{cc}
0 & X \geq T_{1} \\
k P\left(T_{1}-X\right) & X<T_{1}
\end{array}\right\}
$$

Therefore, the expected number of defective items in a production cycle is $E(N)=\int_{0}^{T_{1}} k P\left(T_{1}-X\right) f(X) d X$

Rework occurs at $\mathrm{t}=\mathrm{T}_{1}$. The rework cost includes the set-up cost, material cost etc. The present worth rework cost can be expressed approximately as

$$
\begin{aligned}
& R W=C_{4 v} E(N) e^{-r T_{1}}=C_{4 v}\left\{\int_{0}^{T_{1}} k P\left(T_{1}-X\right) f(X) d X\right\} e^{-r T_{1}} \\
& =C_{4 v} k P\left\{\int_{0}^{T_{1}}\left(T_{1}-X\right) \mu e^{-\mu X} d X\right\} \sum_{0}^{\infty} \frac{\left(-r T_{1}\right)^{n}}{n !}=C_{4 v} k P \mu\left\{T_{1}^{2}-(r+\mu) T_{1}^{3}\right\}
\end{aligned}
$$

Present worth average total cost of the vendor is the sum of holding cost, set up cost, deterioration cost and rework cost.

$$
T C_{v}=\frac{H C_{v}+D C_{v}+S C_{v}+R W}{T}
$$

\subsection{Supplier's Inventory Model}

The change in supplier's inventory level is depicted in Fig. 3b. Supplier has own warehouse (OW) with a fixed capacity of $\mathrm{W}$ units and any quantity exceeding this should be stored in a rented warehouse 
(RW), which is assumed to be available with abundant space. The goods of OW are consumed only after consuming the goods kept in RW.

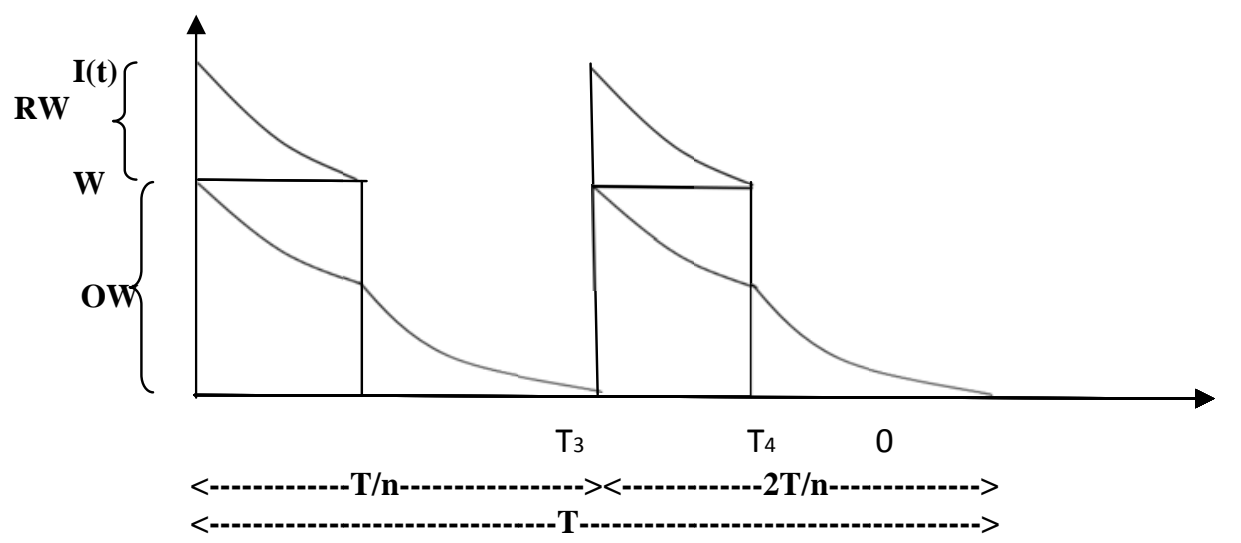

Fig. 1(b) Supplier's inventory system

\subsubsection{Supplier's inventory model for the own warehouse}

In $\mathrm{OW}$, the inventory $\mathrm{W}$ decreases during $\left(0, \mathrm{~T}_{3}\right)$ due to deterioration only, but during $\left(\mathrm{T}_{3}, \mathrm{~T}_{4}\right)$ the inventory is depleted due to both demand and deterioration both.

$$
\begin{array}{ll}
I_{1 s o}{ }^{\prime}(t)=-\zeta I_{1 s o}(t) & 0 \leq t \leq T_{3} \\
I_{2 s o}{ }^{\prime}(t)=-\zeta I_{2 s o}(t)-(\alpha+\beta t) & 0<t \leq T_{4}
\end{array}
$$

Using the boundary conditions $I_{1 \mathrm{so}}(0)=\mathrm{W}$ and $I_{2 s o}\left(\mathrm{~T}_{4}\right)=0$, the solutions of the above differential equations are

$$
\begin{array}{ll}
I_{1 s o}(t)=W e^{-\zeta t} & 0 \leq t \leq T_{3} \\
I_{2 s o}(t)=\left(\frac{\alpha}{\zeta}+\frac{\beta}{\zeta}\left(T_{4}-\frac{1}{\zeta}\right)\right)\left(e^{\zeta\left(T_{4}-t\right)}-1\right) & 0 \leq t \leq T_{3}
\end{array}
$$

Holding Cost in the own warehouse

$$
\begin{aligned}
& H C_{s o}=C_{1 s o}\left[\int_{0}^{T_{3}} I_{1 s o}(t) e^{-r t} d t+e^{-r T_{3}} \int_{0}^{T_{4}} I_{2 s o}(t) e^{-r t} d t\right] \\
& H C_{s o}=C_{1 s o}\left[\frac{W\left(1-e^{-(\zeta+r) T_{3}}\right)}{\zeta+r}+e^{-r T_{3}}\left(\frac{\alpha}{\zeta}+\frac{\beta}{\zeta}\left(T_{4}-\frac{1}{\zeta}\right)\right)\left\{\frac{\zeta e^{-r T_{4}}}{(\zeta+r) r}+\frac{e^{\zeta T_{4}}}{(\zeta+r)}-\frac{1}{r}\right\}\right]
\end{aligned}
$$

\subsubsection{Supplier's inventory model for the rented warehouse}

During the interval $\left(0, \mathrm{~T}_{3}\right)$ the inventory in RW gradually decreases due to demand and deterioration and it vanishes at $\mathrm{t}=\mathrm{T}_{3}$.

$$
I_{s r}{ }^{\prime}(t)=-\eta I_{s r}(t)-(\alpha+\beta t) \quad 0 \leq t \leq T_{3}
$$

Using the boundary condition $I_{\mathrm{sr}}\left(T_{3}\right)=0$, solution of the above differential equation is as

$$
I_{s r}(t)=\left(\frac{\alpha}{\eta}+\frac{\beta}{\eta}\left(T_{3}-\frac{1}{\eta}\right)\right)\left(e^{\eta\left(T_{3}-t\right)}-1\right) \quad 0 \leq t \leq T_{3}
$$

Holding Cost in the rented warehouse

$$
H C_{s r}=C_{1 s r} \int_{0}^{T_{3}} I_{s r}(t) e^{-r t} d t=C_{1 s r}\left(\frac{\alpha}{\eta}+\frac{\beta}{\eta}\left(T_{3}-\frac{1}{\eta}\right)\right)\left\{\frac{\eta e^{-r T_{3}}}{(\eta+r) r}+\frac{e^{\eta T_{3}}}{(\eta+r)}-\frac{1}{r}\right\}
$$


Present worth deterioration cost

$$
\begin{aligned}
D C_{s}=C_{2 s}\left[\zeta\left\{\int_{0}^{T_{3}} I_{s o 1}(t) e^{-r t} d t+e^{-r T_{3}} \int_{0}^{T_{4}} I_{s o 2}(t) e^{-r t} d t\right\}+\eta \int_{0}^{T_{3}} I_{s r}(t) e^{-r t} d t\right] \\
=C_{2 s}\left[\begin{array}{l}
\left.\zeta\left\{\frac{W\left(1-e^{-(\zeta+r) T_{3}}\right)}{\zeta+r}+e^{-r T_{3}}\left(\frac{\alpha}{\zeta}+\frac{\beta}{\zeta}\left(T_{4}-\frac{1}{\zeta}\right)\right)\left\{\frac{\zeta e^{-r T_{4}}}{(\zeta+r) r}+\frac{e^{\zeta T_{4}}}{(\zeta+r)}-\frac{1}{r}\right\}\right\}\right] \\
+\eta\left(\frac{\alpha}{\eta}+\frac{\beta}{\eta}\left(T_{3}-\frac{1}{\eta}\right)\right)\left\{\frac{\eta e^{-r T_{3}}}{(\eta+r) r}+\frac{e^{\eta T_{3}}}{(\eta+r)}-\frac{1}{r}\right\}
\end{array}\right]
\end{aligned}
$$

Present worth set up cost of the supplier is

$S C_{s}=C_{3 s}$

Present worth average total cost of the supplier is the sum of holding cost, set up cost, deterioration cost.

$T C_{s}=\frac{H C_{s o}+H C_{s r}+D C_{s}+S C_{s}}{T / n}$

There are $\mathrm{n}$ deliveries per cycle. The fixed time interval between the deliveries is $T_{3}+T_{4}=T / n$.

\subsubsection{Buyer's Inventory Model}

The buyer's inventory system in Fig. 3(c) can be divided into two independent phases depicted by T5 and T6. Buyer has maximum inventory $\mathrm{MI}_{\mathrm{b}}$. Now buyer's inventory level decreases due to stock dependent demand and deterioration rate up to time $T_{5}$. At time $T_{5}$ there is partial backlogging up to time $\mathrm{T}_{6}$.

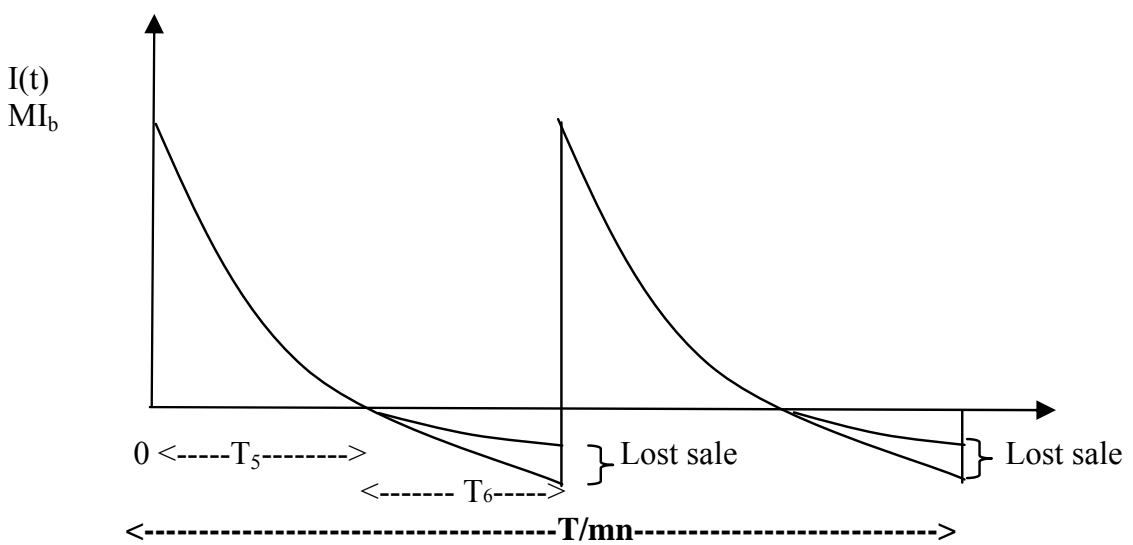

Fig. 1(c) Buyer's inventory system

The differential equations governing to the buyer's inventory level are as follows

$$
\begin{array}{ll}
I_{b 1}{ }^{\prime}(t)=-\theta I_{b 1}(t)-\left(a+b I_{b 1}(t)\right) & 0 \leq t \leq T_{5} \\
I_{b 2}{ }^{\prime}(t)=-\delta a & 0<t \leq T_{6}
\end{array}
$$

By using the boundary condition $I_{b 1}\left(T_{5}\right)=0$ and $I_{b 2}(0)=0$ the solution of the above differential equations are as follows

$$
\begin{array}{ll}
I_{b 1}=\frac{a}{\theta+b}\left(e^{(\theta+b)\left(T_{5}-t\right)}-1\right) & 0 \leq t \leq T_{5} \\
I_{b 2}(t)=-\delta a t & 0<t \leq T_{6}
\end{array}
$$


By using the boundary condition $I_{b 1}(0)=M I_{b}$ we have the buyer's maximum inventory level is

$M I_{b}=\frac{a}{\theta+b}\left(e^{(\theta+b) T_{5}}-1\right)$

Present worth holding cost of the buyer is

$H C_{b}=C_{1 b} \int_{0}^{T_{5}} I_{b 1}(t) e^{-r t} d t=\frac{a C_{1 b}}{\theta+b}\left\{e^{-r T_{5}}\left\{\frac{1}{r}-\frac{1}{\theta+b+r}\right\}+\frac{e^{(\theta+b) T_{5}}}{\theta+b+r}-\frac{1}{r}\right\}$

The present worth deterioration cost is

$D C_{b}=\frac{a C_{2 b} \theta}{\theta+b}\left[e^{-r T_{5}}\left(\frac{1}{r}-\frac{1}{\theta+b+r}\right)+\frac{e^{(\theta+b) T_{5}}}{\theta+b+r}-\frac{1}{r}\right]$

Present worth set up cost of the buyer is

$S C_{b}=C_{3 b}$

Present backlogging cost is

$\mathrm{BA}=C_{4 b} \int_{0}^{T_{6}}-I_{b 2}(t) e^{-r\left(T_{5}+t\right)} d t=a \delta C_{4 b} e^{-r T_{5}}\left[\frac{-e^{-r T_{6}} T_{6}}{r}+\frac{\left(1-e^{-r T_{6}}\right)}{r^{2}}\right]$

Lost sale occurs during the time period 0 to $\mathrm{T}_{6}$. During this time period, the complete shortage is $a T_{6}$ and the partial backlog is $a \delta T_{6}$. Lost sales are the difference between the complete shortage and the partial backlog. Thus, the present worth lost sale cost is

$L S=C_{5 b} a \int_{0}^{T_{6}}(1-\delta) T_{6} e^{-r\left(T_{5}+t\right)} d t=\frac{C_{5 b} a(1-\delta) e^{-r T_{5}} T_{6}\left(1-e^{-r T_{6}}\right)}{r}$

Therefore, the present worth total cost per cycle is

$T C_{b}=\frac{\left(H C_{b}+D C_{b}+S C_{b}+L S+B A\right)}{T / m n}$

There are $m$ deliveries per cycle. The fixed time interval between the deliveries is $T_{5}+T_{6}=T / \mathrm{nm}$.

The average total cost of the model $T C$, which is the sum of Vendor's $\operatorname{cost}\left(T C_{v}\right)$, Supplier's cost $\left(T C_{s}\right)$ and Buyer's cost $\left(T C_{b}\right)$.

$T C=T C_{v}+T C_{v}+T C_{v}$

In order to find optimal values of, $T C, T_{1}, T_{3}$ and $T_{5}$, we have to solve nonlinear equations:

$\partial T C\left(T_{1}, T_{3}, T_{5}\right) / \partial T_{1}=0, \partial T C\left(T_{1}, T_{3}, T_{5}\right) / \partial T_{3}=0$ and $\partial T C\left(T_{1}, T_{3}, T_{5}\right) / \partial T_{5}=0$

\section{Numerical illustration for the model}

In this section, a numerical example is considered to illustrate the model. The following values of parameters are used in the example.

$\mathrm{P}=300$ unit, $\mathrm{C} 1 \mathrm{v}=0.003, \mathrm{C} 2 \mathrm{v}=0.02, \mathrm{C} 3 \mathrm{v}=0.9, \mathrm{C} 4 \mathrm{v}=20, \mathrm{C} 1 \mathrm{so}=0.15, \mathrm{C} 1 \mathrm{sr}=0.21, \mathrm{C} 2 \mathrm{~s}=0.59, \mathrm{C} 3 \mathrm{~s}=0.89$, $\mathrm{C} 1 \mathrm{~b}=3.1, \mathrm{C} 2 \mathrm{~b}=0.3, \mathrm{C} 3 \mathrm{~b}=0.6, \mathrm{C} 4 \mathrm{~b}=0.8, \mathrm{C} 5 \mathrm{~b}=1.2, \mathrm{n}=2, \mathrm{~m}=2, \mathrm{a}=100$ unit, $\mathrm{b}=0.01, \alpha=100$ unit, $\quad \beta=0.09$, $\theta=0.16, \zeta=.07, \eta=.025, \mathrm{~W}=200, \delta=0.06, \mathrm{r}=0.038, \mathrm{k}=0.05, \mu=0.003, \mathrm{~T}=30$ days 
Total Cost

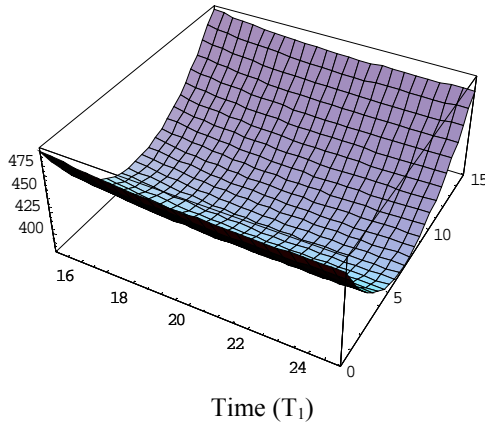

Time $\left(\mathrm{T}_{3}\right)$

Fig. 1. Graphical representation of total cost w.r.t Time.

According to Fig. 1, we can analyze the convexity of the total cost, which shows that our total cost is minimum for the above numerical setup for an optimal value of the $\mathrm{T}_{5}$.

\section{Sensitivity analysis}

The sensitivity of the optimal solution has been analyzed for various system parameters from Table 1 to Table 4 as shown below:

Table 1

Sensitivity analysis w.r.t. cost parameters of the vendor

\begin{tabular}{llcccc}
\hline Parameters & Percentage of change $(\%)$ & $\mathrm{T}_{1}$ & $\mathrm{~T}_{3}$ & $\mathrm{~T}_{5}$ & $(\mathrm{TC})$ \\
\hline $\mathrm{C}_{1 \mathrm{v}}$ & -50 & 21.4122 & 6.82909 & 1.39064 & 378.571 \\
& -25 & 22.1473 & 6.82909 & 1.39064 & 379.927 \\
& +25 & 23.3767 & 6.82909 & 1.39064 & 382.269 \\
& +50 & 23.9046 & 6.82909 & 1.39064 & 383.301 \\
\hline $\mathrm{C}_{2 \mathrm{v}}$ & -50 & 21.4122 & 6.82909 & 1.39064 & 378.571 \\
& -25 & 22.1473 & 6.82909 & 1.39064 & 379.927 \\
& +25 & 23.3767 & 6.82909 & 1.39064 & 382.269 \\
& +50 & 23.9046 & 6.82909 & 1.39064 & 383.301 \\
\hline $\mathrm{C}_{3 \mathrm{v}}$ & -50 & 22.7955 & 6.82909 & 1.39064 & 381.136 \\
& -25 & 22.7955 & 6.82909 & 1.39064 & 381.143 \\
& +25 & 22.7955 & 6.82909 & 1.39064 & 381.158 \\
\hline $\mathrm{C}_{4 \mathrm{v}}$ & +50 & 22.7955 & 6.82909 & 1.39064 & 381.166 \\
& -50 & 26.366 & 6.82909 & 1.39064 & 372.245 \\
& -25 & 24.2319 & 6.82909 & 1.39064 & 377.016 \\
& +25 & 21.7183 & 6.82909 & 1.39064 & 384.859 \\
\hline
\end{tabular}

Table 2

Sensitivity analysis w.r.t. cost parameters of the supplier

\begin{tabular}{llcccc}
\hline Parameters & Percentage of change (\%) & $\mathrm{T}_{1}$ & $\mathrm{~T}_{3}$ & $\mathrm{~T}_{5}$ & $(\mathrm{TC})$ \\
\hline $\mathrm{C}_{1 \mathrm{so}}$ & -50 & 20.8594 & 5.45142 & 1.39064 & 366.582 \\
& -25 & 20.8594 & 6.21779 & 1.39064 & 378.154 \\
& +25 & 20.8594 & 7.33367 & 1.39064 & 397.303 \\
& +50 & 20.8594 & 7.76047 & 1.39064 & 405.565 \\
\hline $\mathrm{C}_{1 \mathrm{sr}}$ & -50 & 22.7955 & 8.58824 & 1.39064 & 361.88 \\
& -25 & 22.7955 & 7.57871 & 1.39064 & 372.602 \\
& +25 & 22.7955 & 6.24077 & 1.39064 & 388.203 \\
& +50 & 22.7955 & 5.76185 & 1.39064 & 394.162 \\
\hline $\mathrm{C}_{2 \mathrm{~s}}$ & -50 & 22.7955 & 6.60172 & 1.39064 & 374.742 \\
& -25 & 22.7955 & 6.71951 & 1.39064 & 377.967 \\
& +25 & 22.7955 & 6.93132 & 1.39064 & 384.295 \\
& +50 & 22.7955 & 7.02695 & 1.39064 & 387.406 \\
\hline $\mathrm{C}_{3 \mathrm{~s}}$ & -50 & 22.7955 & 6.82909 & 1.39064 & 381.121 \\
& -25 & 22.7955 & 6.82909 & 1.39064 & 381.136 \\
& +25 & 22.7955 & 6.82909 & 1.39064 & 381.165 \\
& +50 & 22.7955 & 6.82909 & 1.39064 & 381.180 \\
\hline
\end{tabular}


Table 3

Sensitivity analysis w.r.t. cost parameters of the buyer

\begin{tabular}{llcccc}
\hline Parameters & Percentage of change $(\%)$ & $\mathrm{T}_{1}$ & $\mathrm{~T}_{3}$ & $\mathrm{~T}_{5}$ & $(\mathrm{TC})$ \\
\hline $\mathrm{C}_{1 \mathrm{~b}}$ & -50 & 22.7955 & 06.82909 & 2.2447 & 346.397 \\
& -25 & 22.7955 & 6.82909 & 1.71439 & 368.005 \\
& +25 & 22.7955 & 6.82909 & 1.17117 & 390.027 \\
& +50 & 22.7955 & 6.82909 & 1.01216 & 396.437 \\
\hline $\mathrm{C}_{2 \mathrm{~b}}$ & -50 & 22.7955 & 6.82909 & 1.01492 & 317.908 \\
& -25 & 22.7955 & 6.82909 & 1.2113 & 350.531 \\
& +25 & 22.7955 & 6.82909 & 1.5552 & 409.907 \\
& +50 & 22.7955 & 6.82909 & 1.70797 & 437.26 \\
\hline $\mathrm{C}_{3 \mathrm{~b}}$ & -50 & 22.7955 & 6.82909 & 1.39064 & 381.111 \\
& -25 & 22.7955 & 6.82909 & 1.39064 & 381.131 \\
& +25 & 22.7955 & 6.82909 & 1.39064 & 381.171 \\
\hline $\mathrm{C}_{4 \mathrm{~b}}$ & +50 & 22.7955 & 6.82909 & 1.39064 & 381.191 \\
\hline & -50 & 22.7955 & 6.82909 & 1.41118 & 380.318 \\
& -25 & 22.7955 & 6.82909 & 1.40084 & 380.737 \\
\hline $\mathrm{C}_{5 \mathrm{~b}}$ & +25 & 22.7955 & 6.82909 & 1.3806 & 381.558 \\
& +50 & 22.7955 & 6.82909 & 1.3707 & 381.958 \\
\hline & -50 & 22.7955 & 6.82909 & 1.1874 & 324.113 \\
& +25 & 22.7955 & 6.82909 & 1.28994 & 352.937 \\
\hline
\end{tabular}

\section{Table 4}

Sensitivity analysis w.r.t. deterioration rate for the vendor and buyer's inventory and for the supplier's own and rented warehouse

\begin{tabular}{llllll}
\hline Parameters & Percentage of change (\%) & $\mathrm{T}_{1}$ & $\mathrm{~T}_{3}$ & $\mathrm{~T}_{5}$ & $(\mathrm{TC})$ \\
\hline \multirow{4}{*}{$\Theta$} & -50 & 28.8129 & 6.82909 & 1.47542 & 384.267 \\
& -25 & 24.3554 & 6.82909 & 1.43166 & 382.372 \\
& +25 & 22.3030 & 6.82909 & 1.3521 & 380.93 \\
& +50 & 22.2515 & 6.82909 & 1.31582 & 381.295 \\
\cline { 2 - 7 }$\eta$ & -50 & 22.7955 & 7.16387 & 1.39064 & 377.805 \\
& -25 & 22.7955 & 6.97625 & 1.39064 & 379.697 \\
& +25 & 22.7955 & 6.69939 & 1.39064 & 382.423 \\
& +50 & 22.7955 & 6.57963 & 1.39064 & 383.598 \\
\hline$\zeta$ & -50 & 22.7955 & 5.83421 & 1.39064 & 378.571 \\
& -25 & 22.7955 & 6.35533 & 1.39064 & 379.927 \\
& +25 & 22.7955 & 7.26289 & 1.39064 & 382.269 \\
\hline
\end{tabular}

From the above sensitivity analysis, we can analyze the relative effects of the cost parameters and deterioration rate, on the total cost of the model.

If we study the variation of some other parameters as production rate, percentage of defective items, inflation rate, no of deliveries of the supplier and buyer then we analyze the following results, which give us a previous indication that in future if there is any change in parameters then which parameter is more or less affected on the total cost.

- If we increase the number of delivers of the supplier and buyer then total cost decreases and there is no change in the production time

- This is obvious since with an increment in the percentage of the defective items then the total cost increases.

- If we increase the production rate then the total cost increases very highly and reduces the production time of the vendor.

- As the inflation rate increases the total cost increases. 


\section{Conclusion}

In this research, we have studied a two warehouse supply chain model with some realistic assumptions from the prospective of a vendor, supplier and buyer. The whole model was studied in inflationary environment with variable demand rate. Effect of imperfect items during the production was also discussed. This research motivates us to study on variable demand rate because demand rate effects on production. Concept of imperfect items and two warehouse was very realistic. This model explained the concept of imperfect production processes on the vendor's part and concept of warehouses discussed on the supplier's part. Here supplier considers the two warehouses OW and RW. A numerical assessment of the theoretical model has been considered to illustrate the theory. Sensitivity analysis has been performed in this study by changing the different cost parameters and other parameters. With the help of sensitivity analysis, we can analyze that which parameter is more effective for the total cost and what should be the change occurs in the total cost by changing the values of the parameters. The model can be extended with multi vendors, multi supplier and multi buyers. This could be done in the future research.

\section{References}

Baker, R.C., \& Urban, T.L. (1988). A deterministic inventory system with an inventory leveldependent demand rate. Journal of the Operational Research, 39, (9), 823-831.

Balkhi, Z.T., \& Benkherouf, L. (2004). On an inventory model for deteriorating items with stock dependent and time-varying demand rates. Computers and Operations Research, 31(2), 223-240.

Bhunia, A. K., \& Maiti, M. (1998). A two warehouses inventory model for deteriorating items with a linear trend in demand and shortages. Journal of Operation Research, 49(1), 287-292.

Chern, M.S., Yang, H.L., Teng, J.T., \& Papachristos, S. (2008). Partial backlogging inventory lot size models for deteriorating items with fluctuating demand under inflation. European Journal of Operational Research, 191(1), 127-141.

Chen, L.H., \& Kang, F.S. (2010). Coordination between vendor and buyer considering trade credit and items of imperfect quality. International Journal of Production Economics, 123(1), 52-61.

Chung, K.J., \& Hou, K.L. (2003). An optimal production runtime with imperfect production processes and allowable shortages. Computers and Operations Research, 20(1), 483-490.

Chung, K.J., Her, C.C., \& Lin, S.D. (2009). A two-warehouse inventory model with imperfect quality production processes. Computers \& Industrial Engineering, 56(1), 193-197.

Chung, K.J., \& Huang, Y.F. (2006). Retailer's optimal cycle times in the EOQ model with imperfect quantity and a permissible credit period. Quality \& Quantity, 40(1), 59-77.

Das, B., Maity, K., \& Maiti, M. (2007). A two warehouse supply-chain model under possibility/necessity/credibility measures. Mathematical and Computer Modelling, 46(3-4), 398409.

Geraldine, S., \& Yves, P. (2010). An integrated model for warehouse and inventory planning. European Journal of Operation Research, 204(1), 35-50.

Goswami, A., \& Chaudhuri, K. S. (1992). An economic order quantity model for items with two levels of storage for a linear trend in demand. Journal of Operational Research, 43(2), 157-167.

Ho, C.H, Ouyang, L.Y., \& Su, C.H. (2006). Analysis of optimal vendor-buyer integrated inventory policy involving defective items. International Journal of Advanced Manufacturing Technology, 29(11-12), 1232-1245.

Hsu, P.H. (2012). Optimal production policy with investment on imperfect production processes. African Journal of Business Management, 6(1), 67-79.

Hartley, V. R. (1976). Operations research - a managerial emphasis California. Good Year Publishing Company, 315-317.

Khouja, M., \& Mehrez, A. (1994).An Economic Production Lot Size Model with Imperfect Quality and Variable Production Rate. Journal of Operational Research, 45(12), 1405-1417.

Lee, C.C., \& Hsu, S.L. (2009). Two Warehouse production model for deteriorating inventory items 
with time-dependent demands. European Journal of Operational Research, 194(3), 700-710.

Lin, C.S. (1999). Integrated production-inventory models with imperfect production processes and a limited capacity for raw materials. Mathematical and Computer Modelling, 29(2), 81-89.

Mandal, M., \& Maiti, M. (1997). Inventory model for damageable items with stock-dependent demand and shortages. Opsearch, 34(3), 155-166.

Maddah, B., \& Jaber, M.Y. (2008). Economic order quantity for items with imperfect quality. International Journal of Production Economics, 112(2), 808-815.

Porteus, E. L. (1986). Optimal lot sizing, process quality improvement and setup cost reduction. Operations Research, 18(1), 137-144.

Rosenblatt, M.J., \& Lee, H.L. (1986). Economic production cycles with imperfect production processes. IIE Transactions, 18(1), 48-55.

Sarkar, B., \& Moon, I. (2011). An EPQ model with inflation in an imperfect production system. Applied Mathematics and Computation, 217(13), 6159-6167.

Yang, H.L. (2004). Two warehouse inventory models for deteriorating items with shortages under inflation. European Journal of Operation Research, 157(2), 344-356.

Yang, H.L. (2006). Two warehouse partial backlogging inventory models for deteriorating items under inflation. International Journal of Production Economics, 103(2), 362-370.

Yang, H. L., Teng, J. T., \& Chern, M. S. (2010). An inventory model under inflation for deteriorating items with stock dependent consumption rate and partial backlogging shortages. International Journal of Production Economics, 123(1), 8-19.

Salameh, M.K., \& Jaber, M.Y. (2000). Economic production quantity model for items with imperfect quantity. International Journal of Production Economics, 64(1-3), 59-64.

Wee, H.M., Yu, J., \& Chen, M.C. (2007). Optimal inventory model for items with imperfect quality and shortage backordering. Omega Naval Research Logistics, 35(1), 7-11. 